\title{
Kinetic regularities of alloying iron-carbon alloys with vanadium
}

\author{
Alexander $\mathrm{Klimov}^{1, *}$ and Michael Zinigrad ${ }^{2}$ \\ ${ }^{1}$ Institute of New Materials and Technologies, Ural Federal University, 620002 Yekaterinburg, Russia \\ ${ }^{2}$ Department of Chemical Engineering, Ariel University, Ariel,40700, Israel
}

\begin{abstract}
The results of the vanadium reduction laboratory investigation are presented. Experiments were conducted with $\mathrm{CaO}-\mathrm{SiO}_{2}-\mathrm{Al}_{2} \mathrm{O}_{3}-\mathrm{V}_{2} \mathrm{O}_{3}$ slags in a wide range of compositions in an air atmosphere. A saturated ironcarbon melt was used as a reducing agent. The reduction kinetics was studied by sampling. $\mathrm{V}_{2} \mathrm{O}_{3}$ reduction from slags having a viscosity of more than 0.5 $\mathrm{Pa} \cdot \mathrm{s}$ and containing less than $7.5-8.0 \% \mathrm{~V}_{2} \mathrm{O}_{3}$ proceeds in a diffusion mode. The reaction is of the first order in vanadium. The process rate is inversely proportional to the square root of slag viscosity. A good agreement between the obtained data and the results of electrochemical studies on the cathodic reduction of vanadium was found. One made possible to deduce the rate equation of vanadium reduction by an iron-carbon melt depending on the volume concentration, temperature and slag viscosity. The calculated data for different slags acceptably check with those found by experiment.
\end{abstract}

\section{Introduction}

Vanadium is used in many industries and applications, from automobiles, power generation, and hand tools, to ships, industrial tools and aeroplanes. Improving the structure of structural and cast steels during microalloying, vanadium leads to grain refinement, to an increase in strength, hardenability, endurance under alternating loads and wear resistance of products. The introduction of vanadium improves the weldability of steel and increases its cold resistance [1-3]. An economically viable way of introducing vanadium into an iron-carbon alloy is direct microalloying through the use of converter vanadium slags. In this case, the kinetics of vanadium reduction from slags by an iron-carbon melt becomes a practically important issue. The alloying processes of steels with vanadium are described in sufficient detail [4]. However, continuous improvement and efficiency increasing of the existing technologies requires a detailed investigation of the vanadium redox reactions mechanisms. Meanwhile, the physicochemical problems of vanadium metallurgy are solved to a lesser extent than the technological ones. In particular, the number of works on the reduction kinetics of vanadium by iron-carbon melts is limited [5-9]. From these studies data it follows that the rate of vanadium reduction from industrial slags is a 4-5 times less than from synthetic slags with the vanadium oxides addition. The reduction rate of $\mathrm{V}_{2} \mathrm{O}_{5}$ is twice as

* Corresponding author: a.v.klimov@urfu.ru 
many as $\mathrm{V}_{2} \mathrm{O}_{3}$. The transition from an air atmosphere to an argon atmosphere increases the rate of 1.5-2.0 times.

According to the considered and other works [10-12], it is difficult to express an opinion on the kinetics and mechanism of vanadium reduction. In ferrous slags, probably, the main part of vanadium is in the trivalent form and enters the spinel refractory phase, the dissolution of which in the homogeneous part of the slag can limit the complete reduction process. The vanadium reduction from the homogeneous part of the slag can be specified either by diffusion of vanadium in the slag, or by the carbon anodic oxidation stage. The kinetic equations in reviewed articles are not available. The influence of slag composition and temperature on the reduction rate is not revealed.

\section{Experimental procedure and materials}

We have investigated the reduction kinetics of vanadium from various compositions slags by a saturated iron-carbon melt. The experiments were carried out by sampling in a resistance furnace with a coal heater. The working space of furnace was isolated from the heater with a corundum tube, which provided an air atmosphere. Slag samples were taken with a tungsten rod and quenched in water. Metal samples were aspirated by a quartz capillary. Graphite and corundum crucibles were used. Corundum tubes were inserted into graphite crucibles to fix the slag - graphite contact area when slags foaming. The visible contact surface was taken into account. When working with corundum crucibles a graphite disc was pressed into bottom of the cylindrical corundum crucible. A pig iron portion, previously produced in a graphite crucible, was placed on a base. The previously prepared vanadium-containing slag was loaded over it, and the crucible put into the preheated furnace. To melt the slag and establish the experimental temperature took no more than 1-2 minutes. After the system was held for a certain time at a given temperature, the cell was quenched in water and broken. The metal - slag interface and the phase concentration of the reagents were determined. The temperature in the experiments was controlled by a platinum-rhodium or tungsten-rhenium thermocouples.

In the course of the experiments, there was a joint reduction of $\mathrm{V}, \mathrm{Si}, \mathrm{Ti}$, as well as dissolution of $\mathrm{Al}_{2} \mathrm{O}_{3}$ crucible material in slag. There was a change in mass due to sampling. Therefore, the change in the component concentrations in the metal and slag was influenced by many factors, which were taken into account by take a mass balance over all elements. The components reduction rate was determined by differentiating the mass-time dependences of the component. The Table 1 shows the initial compositions of the slag (without additives $\left.\mathrm{V}_{2} \mathrm{O}_{3}\right)$.

\section{Results and discussion}

During two hours vanadium from slags 2-9 was almost completely reduced. The concentration of vanadium in the slag was staying at a constant level. For slags 5-8 10-30 min exposure was sufficient until a constant vanadium concentration was staying. Most of vanadium was reduced by crucible carbon, probably due to the larger contact surface.

According to the dependence of the vanadium reduction rate on the vanadium concentration in metal or slag all the studied melts can be divided into two groups. In viscous slags $1-4,9(\mu \geq 0.5-0.6 \mathrm{~Pa} \cdot \mathrm{s})$, the reduction rate decreases in proportion to the concentration in the metal (Figure 1), therefore, the reaction is of the first order in vanadium. A straight line shows a bend due to intensive vanadium reduction also by solid carbon in the initial period. The first order reaction for vanadium probably indicates diffusion difficulties. 
Table 1. The initial compositions of the investigated slags (wt.\%), their viscosity $(\mu)$ at experimental temperatures, and initial reduction rates $\left(\mathrm{v}_{\mathrm{i}}\right)$ of $\mathrm{V}$ and $\mathrm{Si}$

\begin{tabular}{|c|c|c|c|c|c|c|c|}
\hline No. & $\mathrm{CaO}$ & $\mathrm{SiO}_{2}$ & $\mathrm{Al}_{2} \mathrm{O}_{3}$ & $\frac{\mathrm{CaO}}{\mathrm{SiO}_{2}}$ & $\begin{array}{c}\mu, \\
\mathrm{Pa} \cdot \mathrm{s}\end{array}$ & $\begin{array}{c}v_{\mathrm{v}} \cdot 10^{7}, \\
\mathrm{~mol} /\left(\mathrm{sm}^{2} \cdot \mathrm{s}\right)\end{array}$ & $\begin{array}{c}v_{\mathrm{Si}} \cdot 10^{7}, \\
\mathrm{~mol} /\left(\mathrm{sm}^{2} \cdot \mathrm{s}\right)\end{array}$ \\
\hline 1 & 11.9 & 65.9 & 22.2 & 0.181 & $19-44$ & 3.2 & 72.0 \\
\hline 2 & 28.7 & 49.0 & 22.3 & 0.586 & $1.4-1.8$ & 10.1 & 43.0 \\
\hline 3 & 33.6 & 43.8 & 22.6 & 0.767 & $1.2-2.0$ & 16.1 & 85.0 \\
\hline 4 & 38.0 & 40.2 & 21.8 & 0.945 & 0.35 & 24.2 & 85.0 \\
\hline 5 & 41.2 & 38.1 & 20.7 & 1.081 & $0.55-0.82$ & 27.4 & 72.0 \\
\hline 6 & 40.5 & 30.6 & 28.9 & 1.322 & 0.55 & 38.3 & 55.0 \\
\hline 7 & 47.9 & 26.1 & 26.0 & 1.835 & 0.26 & 27.4 & 1.4 \\
\hline 8 & 49.3 & 21.5 & 29.2 & 2.291 & $0.14-0.34$ & 32.2 & 2.7 \\
\hline 9 & 61.6 & 19.0 & 19.4 & 3.242 & 7 & 29.8 & 9.6 \\
\hline
\end{tabular}

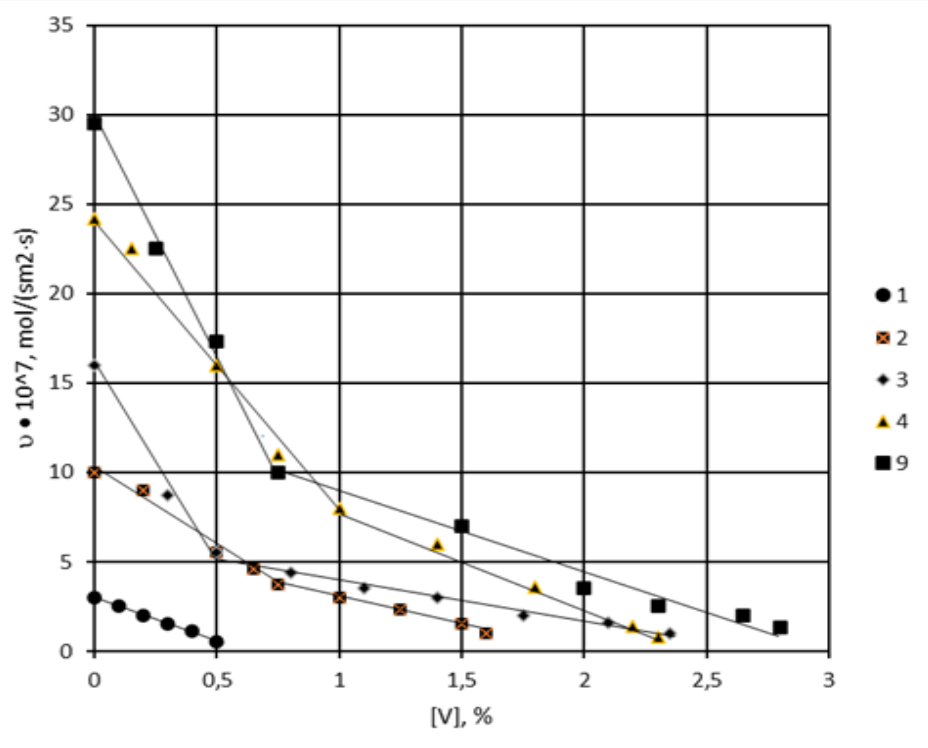

Fig. 1. Dependence of vanadium reduction rate from slags 1-4, 9 on the vanadium content in metal (line numbers correspond to the numbers of slags)

The initial reduction rate of vanadium increases rapidly with basicity of slag increase from 0.18 to 0.95 (Table 1) and with bases greater than 1.1 the rate remains at about the same level. In terms of a mole of vanadium, it turned out to be about twice as high as when reducing by solid carbon. When the vanadium reduction is slowed down, the silicon reduction process is accelerated and does not reach equilibrium by the experiment time is completed. 
To obtain generality influence of the slag composition on the vanadium reduction rate, the viscosity of the initial slag without taking into account $\mathrm{V}_{2} \mathrm{O}_{3}$ additives was estimated from literature data. It turned out that the initial vanadium reduction rate linearly depends on $\mu^{-1 / 2}$ (Figure 2). This dependence may be results of the diffusion process mode. It can be shown that when slag flow moves along the metal surface, the diffusion layer thickness is proportional to the square root of viscosity [13]. As shown by an x-ray introscope, such a phase motion is caused by the gas bubbles flow.

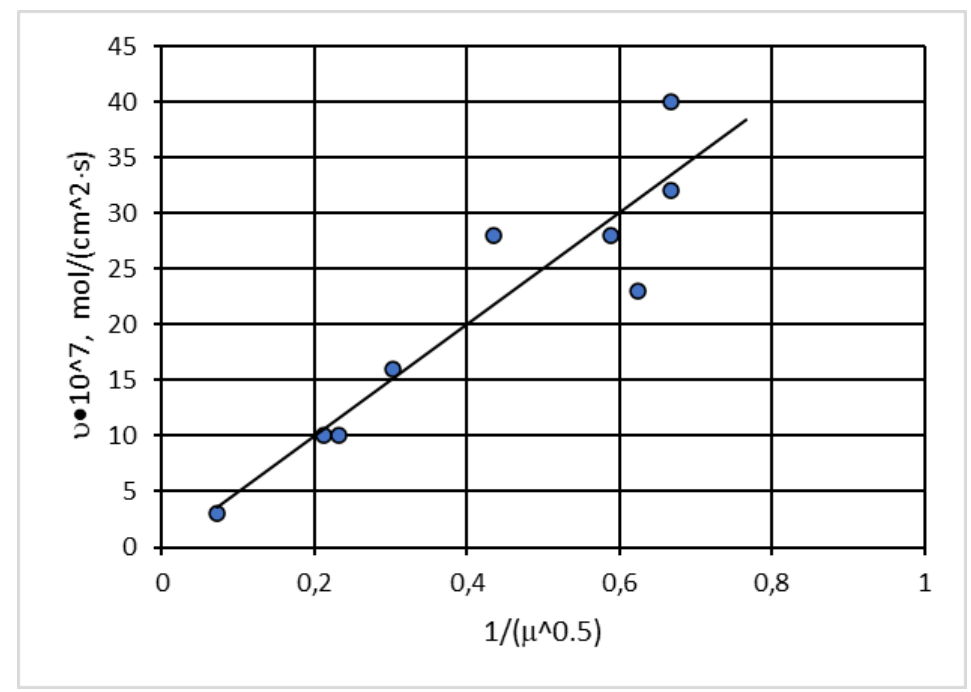

Fig. 2. Dependence of the vanadium reduction rate on slag viscosity

The vanadium reduction rate $\left(2.42 \cdot 10^{-6} \mathrm{~mol} /\left(\mathrm{cm}^{2} \cdot \mathrm{s}\right)\right)$ found for slag based on (wt.\%) $40 \mathrm{CaO}, 40 \mathrm{SiO}_{2}, 20 \mathrm{Al}_{2} \mathrm{O}_{3}$ was compared with that calculated using electrochemical data $[14$, $15]$. Under the same conditions, the half-reaction (1) rate amounted to $2.6 \cdot 10^{-6} \mathrm{~mol} /\left(\mathrm{cm}^{2} \cdot \mathrm{s}\right)$.

$$
\mathrm{V}^{3+}+3 \mathrm{e}=\mathrm{V}^{0}
$$

A good agreement between the experimental and calculated rates obtained by various independent methods indicates the identity of the processes occurring in both cases. Therefore, it can be assumed that the reduction of $\mathrm{V}_{2} \mathrm{O}_{3}$ from slags by an iron-carbon melt has an electrochemical character and is probably limited by the trivalent vanadium ions diffusion in the slag.

In the diffusion mode, the cathode current density is, $\mathrm{A} / \mathrm{cm}^{2}$

$$
i=i_{d}\left[1-\exp \left(-\frac{n F}{R T} \eta\right)\right]
$$

where $i_{d}$ is the ultimate cathode current density, $\mathrm{A} / \mathrm{cm}^{2}$.

Taking into account the ultimate current density, equation (2) can be written as

$$
i=\frac{D_{V^{3}}+\frac{3 F C_{V}^{0}}{\delta}}{A_{V}}\left[1-\exp \left(-\frac{n F}{R T} \eta\right)\right]
$$

where $\frac{D_{V^{3+}}}{\delta}$ is the mass transfer coefficient $\mathrm{V}^{3+}$ in the slag found earlier [14,15]; $\mathrm{C}_{V}^{o}$ is the volume vanadium concentration in slag, $\mathrm{g} / \mathrm{cm}^{3} ; A_{V}$ is the atomic mass of vanadium, $\mathrm{g} / \mathrm{mol} ; F$ is Faraday number and $\eta$ is cathode polarization, $\mathrm{V}$.

Assuming that the carbon anode discharge is the most electronegative and slightly changing, we chose the carbon polarization $\left(\eta_{c}\right)$ as start counting. Then the value of $\eta$ can be 


$$
\eta=\eta_{\mathrm{C}}-\eta_{V}=\frac{R T}{3 F} \ln \left(\frac{K}{P}\right)
$$

where $\frac{K}{P}$ is the ratio of the equilibrium constant to the activities product for the reaction

$$
\left(\mathrm{V}_{2} \mathrm{O}_{3}\right)+3[\mathrm{C}]=2[\mathrm{~V}]+3\{\mathrm{CO}\}
$$

The current density is related to reduction rate by the ratio

$$
v=\frac{i}{3 F}
$$

A combination of equations (3),(4),(6) and the substitution of known numerical constants values gives the vanadium reduction rate equation in the form

$$
v=1,382 \cdot 10^{-5} \mathrm{C}_{V}^{0}\left[1-\left(\frac{P}{\mathrm{~K}}\right)^{\frac{3}{2}}\right]
$$

Taking into account the activation energy of trivalent vanadium diffusion in the slag (145 $\mathrm{kJ} / \mathrm{mol}$ ) $[14,15]$ and the relationship between the vanadium reduction rate and the viscosity of the slag as shown in Figure 2, it is possible to present equation (7) in the form

$$
v=1,382 \cdot 10^{-5} \exp \left[9,572\left(1-\frac{1823}{T}\right)\right] C_{V}^{0}\left(\frac{\mu_{0}}{\mu}\right)^{1 / 2}\left[1-\left(\frac{P}{\mathrm{~K}}\right)^{\frac{3}{2}}\right]
$$

where $\mu_{0}$ is the slag (wt.\%) $40 \mathrm{CaO}, 40 \mathrm{SiO}_{2} 20 \mathrm{~A}_{2}{ }_{2} \mathrm{O}_{3}$ viscosity at a given temperature, $\mu$ is the test slag viscosity at this temperature.

The rates calculated by equation (8), within the experimental error, given the inaccuracy in viscosities of the investigated slags estimating, were in good agreement with the experimental vanadium recovery rates as shown in Figure 3.

This is an indirect corroboration of the electrochemical nature and diffusion mode of trivalent vanadium reduction from slags by iron-carbon melt. It should be noted that these results were obtained in air. In blast-furnace smelting conditions, vanadium should mainly be in a divalent state. For $\mathrm{V}^{2+}$ ions, the mass transfer coefficients are 5-7 times lower than for $\mathrm{V}^{3+}$, and the activation energy is about $170 \mathrm{~kJ} / \mathrm{mol}$. In addition, the equilibrium constant of the reduction reaction is significantly different. Therefore, equation (8) can only be used for trivalent vanadium.

\section{Conclusion}

Studies of the kinetics of vanadium reduction by an iron-carbon melt from slags of $\mathrm{CaO}$ $\mathrm{SiO}_{2}-\mathrm{Al}_{2} \mathrm{O}_{3}-\mathrm{V}_{2} \mathrm{O}_{3}$ system in a wide range of compositions showed that $\mathrm{V}_{2} \mathrm{O}_{3}$ reduction from slags having a viscosity of more than $0.5 \mathrm{~Pa} \square \mathrm{s}$ and containing less than $7.5-8.0 \% \mathrm{~V}_{2} \mathrm{O}_{3}$ proceeds in a diffusion mode. The process rate is inversely proportional to the square root of slag viscosity. The equation of the reduction rate is obtained depending on the slag viscosity, temperature and vanadium concentration. 


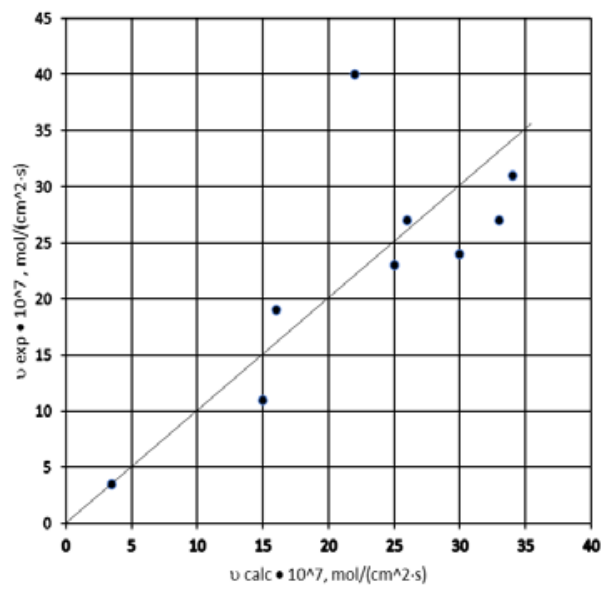

Fig. 3. Comparison of experimental and calculated by the equation (8) vanadium reduction rates.

\section{References}

1. T. N. Baker, Materials Science and Technology, 25, 9,1083, (2009)

2. R. Lagneborg, B. Hutchinson, T. Siwecki and S. Zajac, The Role of Vanadium in Microalloyed Steels, Dedicated to the Memory of Michael Korchynsky, KIMAB, Sweden, (2014)

3. B. Hutchinson, D. Martin, O. Karlsson, F. Lindberg, H. Thoors, R. K. W. Marceau and A. S. Taylor, Materials Science and Technology, 33, 4, 497, (2016)

4. A. A. Filippenkov, Yu. A. Deryabin and L. A. Smirnov, Effective steel alloying technologies with vanadium, Ural Branch of the Russian Academy of Sciences, Russia, (2001)

5. L. A. Smirnov, B. I. Topychkanov and V. D. Shantarin, Proceedings of Higher Educational Institutions. Ferrous metallurgy, 12, 43, Russia (1969)

6. L. A. Smirnov, V. D. Shantarin and Yu. S. Schekalev, Izv. AN SSSR. Metally, 3, 42, Russia, (1970)

7. V. D. Shantarin and L. A. Smirnov, Russian Journal of Physical Chemistry, 44, 344, Russia, (1970)

8. A. A. Vostryakov and B. M. Lepinskykh, Physical Chemistry of Metallurgical Melts, UFAN RAN, 20, 150, Russia, (1969)

9. V. G. Tsikarev, A. I. Pastukhov and S. I. Popel, Steel production, UralNIICHM, 16, 18, Russia, (1972)

10. Q. Liu, C. Li, D. Zou and J. Sun, Acta Metall Sin, 29, 5, 49, (1993)

11. Z. Zhuang, J. Chen, B. Meng and S. Zheng, in Proceedings of the The Minerals, Metals \& Materials Society TMS 144th Annual Meeting \& Exhibition, Springer, Cham, 911, (2015)

12. X. Zeng, Y. Wang, H-Y. Li, B. Xie and J. Diao, in Proceedings of the 5th International Symposium on High-Temperature Metallurgical Processing SanDiego Californya USA, 295, (2014)

13. V. G. Levich, Physicochemical hydrodynamics, Moscow, Fizmatgiz, Russia (1959)

14. A. V. Klimov, Physicochemical Investigations of Metallurgical Processes, UPI, 11, 112, Russia, (1983)

15. G. A. Toporishchev, A. V. Klimov and A. I. Polyakov, Electrode processes in halide and oxide electrolytes, UNC AN SSSR, 43, Russia, (1981) 